\title{
Las escuelas públicas en el Colegio de San Ignacio de Loyola 1793-1844
}

\author{
Public schools at the Colegio \\ San Ignacio de Loyola, 1793-1844 \\ Andrea Torres Alejo ${ }^{1}$
}

\section{Resumen}

Este artículo estudia las escuelas públicas instaladas en el Colegio de San Ignacio de Loyola de 1793 a 1844. Las escuelas públicas de "San Luis Gonzaga" eran gratuitas y estaban destinadas a las niñas pobres. Como escuelas de primeras letras, las niñas aprendían a leer, a escribir, las operaciones básicas de la aritmética, el catecismo; así como las labores propias de su sexo: la costura y el bordado. El análisis de estas escuelas abre una ventana hacia el pasado educativo de las mujeres, en el cual las concepciones culturales propias de la época, determinaron los conocimientos y aprendizajes que ellas debían tener. De acuerdo con lo anterior, en esta investigación se ha hecho uso de una metodología basada en la historia social y cultural de la educación, la cual permite explicar tanto los contenidos educativos, los procesos de aprendizaje y las interacciones de nuestros antepasados con su realidad histórica. Además, este artículo busca ser una contribución al acercamiento y conocimiento de las mujeres y su educación en el pasado, siguiendo los planteamientos de la actual historiografía de la educación en la cual se ha abierto la posibilidad de abordar diversas temáticas educativas, como es el caso de la educación femenina. En este sentido, las niñas que asistieron a las escuelas públicas de "San Luis Conzaga" recibieron enseñanzas de carácter formal, pues además de seguir el método de las escuelas lancasterianas, también se crearon reglamentos específicos para su instrucción. Las conclusiones a las que se han llegado, refieren que dichos establecimientos siguieron un modelo educativo que era funcional, así como económico. Estas escuelas públicas fueron pensadas para estar al alcance de las familias pobres que deseaban enviar a sus hijas, hermanas, o de cualquier otro parentesco, a estudiar, sin tener que cumplir con los requisitos estrictos que se establecieron para el Colegio de San Ignacio de Loyola.

\section{Palabras clave: Colegio, educación, escuelas públicas, niñas, maestras.}

\footnotetext{
${ }^{1}$ Doctora en Historia. Institución de Adscripción: Instituto Iberoamericano de Historia de la Educación y Cultura Escolar. Líneas de investigación: Historia de la ciencia en México en el siglo XX; las redes y sociedades científicas mexicanas y la Historia de la Educación en México; la instrucción femenina en el siglo XIX y XX y el currículo científico en la enseñanza media superior y superior en México finales del siglo XIX y siglo XX. Correo electrónico: andytorresalejo@ gmail.com
} 


\begin{abstract}
This article is about the public schools installed at the Colegio de San Ignacio de Loyola, from 1793 to 1844. The public schools "San Luis Gonzaga" were tuition free and were intended for poor girls. As they were schools of first letters, the girls learned to read and write, as well as basic knowledge of arithmetic and catechism; finally, they learned the work tied to their sex: sewing and embroidery. The analysis of these schools opens a window toward the educational past of women in which the cultural conceptions of the time determined the knowledge and learning that they should have. In accordance with the above, this research has employed a methodology based on the social and cultural history of education, which allows to explain both the educational contents, the learning processes and the interactions of our ancestors with their historical reality. Beyond this, the present article looks forward to make a contribution to women's knowledge and education in the past, following the arguments of present historiography of education in which the possibility to explore different topics - for example "female education" - has been opened. In this sense, the girls who assisted to the public schools "San Luis Gonzaga" received formal teaching because, beyond following the method of Lancaster schools, they also created specific rules for the instruction. The conclusions reached in this article point out to the fact that such establishments followed an educational model which was functional as well as economic. These public schools were designed to be at the reach of poor families who wished to send their daughters, sisters or relatives, to study without having to fulfill the strict requirements which were established for the Colegio de San Ignacio de Loyola.
\end{abstract}

\title{
Keywords: College, Education, Public Schools, Girls, Teachers.
}

\section{Introducción}

La actual historiografía de la educación en México ha puesto énfasis en objetos de estudio y actores sociales que anteriormente no habían sido considerados. En este sentido, la reconstrucción de la historia de las mujeres ha cobrado relevancia. Su visibilización forma parte de una nueva escritura de la historia. Investigadoras como Pilar Foz y Foz, Josefina Muriel, Julia Tuñón, Luz Elena Galván y Oresta López Pérez, entre otras, han mostrado y demostrado la relevancia histórica de las mujeres al ponerlas como protagonistas de sus reconstrucciones históricas; las han sacado del olvido y han explicado que, como sujetos históricos, han sido "estereotipadas, negadas, invisibilizadas y sometidas a imaginarios sociales, entendidos como representaciones compartidas por un grupo social que le permiten establecer regulaciones y autorregulaciones al orden social" (Galván, 2008: 11). 
La historiografía de la educación en México es el resultado de un proceso académico e intelectual, el cual surgió a finales de la década de los años setenta del siglo XX y que se fue concretando en los años ochenta y noventa hasta nuestros días. Este proceso de cambio en la escritura de la historia de la educación se originó por "la influencia de las ciencias sociales y de una historiografía renovada" (Meníndez, 2009: 152). Actualmente, la historia e historiografía de la educación en México se han consolidado como áreas académicas y de investigación. Los historiadores que se han dedicado a ella han logrado institucionalizar tanto su disciplina como su comunidad académica, han abierto la brecha a nuevos temas de investigación y al análisis de nuevos objetos de estudio. Hoy en día esto resulta evidente, pero hace casi tres décadas apenas se comenzaban a plantear estas posibilidades, mismas que se hicieron palpables cuando, en el año 2003, fue publicado el libro Historiografía de la educación en México, coordinado por Luz Elena Galván Lafarga, Susana Quintanilla Osorio y Clara Inés Ramírez González.

La obra es el tomo X de la colección titulada La investigación educativa en México, que publicó el Consejo Mexicano de la Investigación Educativa (COMIE); el contenido que las autoras coordinaron da cuenta del tipo de investigaciones que se realizaron en el decenio de 1992-2002 sobre las cuestiones educativas en nuestro país. La revisión y lectura de este texto permite comprender los enfoques teóricos y metodológicos que los historiadores estaban empleando. En él se puede ver que en la historiografía de la educación mexicana se estaban incorporando nuevos elementos de investigación e interpretación, pues a partir de ese momento, quedaba claro que dichas aportaciones historiográficas se nutrían de la interdisciplina; de tal manera que los cuestionamientos hechos por los historiadores podían ser resueltos con ayuda de teorías y metodologías propias de otras disciplinas sociales y humanistas.

La historia de la educación se iba modernizando pues, "tradicionalmente", las historias que se habían reconstruido trataban sobre la legislación educativa, las normas o las prácticas, personajes destacados; es decir, "ofrecían a los lectores una visión general de dichos procesos" (González, 2003: 28). Esta generalización, en cierta medida, dejó de lado otros aspectos de las dinámicas escolares, pues las anteriores reflexiones no mostraban los matices que había, por ejemplo, entre las regiones, así como las diferencias entre la escala global con la local.

Las mujeres, los niños, los jóvenes, los campesinos o los maestros, fueron sacados del olvido y del silencio de la historia oficial, hecho que también ha sucedido con otros elementos que han formado parte de los procesos educativos como las escuelas, la cultura escolar, la vida cotidiana, los libros escolares, las revistas y los periódicos educativos, por mencionar algunos ejemplos. Lo anterior ha permitido ver que la educación en el pasado se daba por dos vías: la formal y la informal. La primera de ellas tiene que ver con lo institucional, con los planes y programas de estudio y con una educación que se daba al interior de las aulas (Diccionario de historia de la educación, 2002). La segunda se refiere a aquella que no sigue un programa o 
plan educativo específico (Diccionario de historia de la educación, 2002); es decir, es la que se aprendía en casa o a través de la lectura de periódicos y revistas.

En el caso que se abordará en este artículo, es decir, la educación de las niñas que ingresaron a las escuelas públicas de "San Luis Gonzaga", se puede hablar de una educación de carácter formal. Dichas escuelas fueron instaladas en el Colegio de San Ignacio de Loyola, un establecimiento particular que había sido fundado en la capital de la Nueva España por vascos y navarros agrupados en la cofradía de Nuestra Señora de Aránzazu. Dicho colegio era la principal obra asistencial de esta comunidad en la capital del virreinato y en él se albergaban y resguardaban de los peligros de la vida diaria a mujeres españolas vulnerables: viudas y huérfanas, preferentemente las de origen vascongado. Cuando las escuelas públicas fueron dispuestas en el colegio, éste ya contaba con más de dos décadas de existencia y era reconocido tanto por sus prácticas asistenciales como de instrucción femenina.

Las escuelas públicas del Colegio de San Ignacio de Loyola son interesantes, pues a diferencia de los requisitos de ingreso que se establecieron para las colegialas, entre ellos la limpieza de sangre, las niñas que asistieron a las escuelas de "San Luis Gonzaga" podían ser de cualquier condición racial. Para los vascongados residentes en la capital de la Nueva España, la educación de la mujer era un asunto importante, el cual debía ser apoyado y propiciado, de allí que tomaran la decisión de abrir estos establecimientos.

Este artículo está organizado en dos apartados. En el primero se describe, de manera general, cómo era la educación de los niños y niñas en el pasado. Se hace mención sobre qué era la enseñanza elemental y qué era lo que se entendía por escuelas públicas, esto con el objetivo de comprender la dinámica escolar que se siguió en las escuelas públicas de "San Luis Gonzaga" establecidas en el Colegio de San Ignacio de Loyola. En el segundo apartado se aborda el análisis de dichas escuelas, se explica por qué fueron abiertas, así como la importancia de las maestras y el modelo educativo que era utilizado para enseñarles a las niñas.

\section{La enseñanza de primeras letras, las escuelas públicas y la instrucción de las mujeres}

En el virreinato de la Nueva España, los niños podían ser instruidos en diversos establecimientos, pues no existía un sistema educativo tal y como lo concebimos hoy en día. Lo que ahora se puede denominar como educación primaria, en el pasado se conoció como educación elemental y los maestros que enseñaban formaban parte del "nobilísimo arte de leer y escribir" (Gonzalbo, 1990: 26). Los padres de niños que pertenecían a familias acaudaladas podían solicitar el servicio de un maestro o preceptor. Por su parte, aquellos que no tenían la solvencia económica, pero que deseaban que sus hijos fueran instruidos, los podían enviar a 
las escuelas públicas establecidas en alguna parroquia, convento o en la casa de algún particular. También existieron los establecimientos denominados de "amiga", destinados principalmente para las niñas entre tres y doce años y para los niños menores de cinco. En estos últimos, básicamente se enseñaba la doctrina cristiana y algunos rudimentos de primeras letras, pues las mujeres que estaban a cargo de los niños no eran consideradas como "maestras" ya que ellas no tenían acceso a la examinación y por tanto no obtenían la licencia o el permiso para ejercer dicha profesión.

La instrucción "elemental" o de "primeras letras" se refería a la enseñanza y aprendizaje de la lectura, la escritura y la aritmética elemental (Gonzalbo, 1990: 34), el interés que se tenía era que los niños sólo aprendieran a leer y escribir. La educación era diferenciada; es decir, que a los niños y a las niñas no se les enseñaba lo mismo, pues cuando ellos crecieran, se desenvolverían en ámbitos que también estaban diferenciados. Al sexo masculino le correspondía la vida pública, es decir, la ocupación de cargos y puestos públicos o la milicia, es por esta razón, que una vez que aprendían a leer y escribir podían ingresar a otras instituciones educativas en las que recibían una formación de carácter superior. Por otro lado, la parte femenina tenía para sí los asuntos privados: el matrimonio, la maternidad y la familia, de allí la necesidad de inculcar en ellas cuestiones morales y las buenas costumbres.

Esta forma de educar e instruir a los niños se mantuvo vigente durante los dos primeros siglos virreinales. Al llegar el siglo XVIII, se empezaron a originar nuevos planteamientos que buscaban modernizar la educación tanto en la Metrópoli como en los territorios ultramarinos. Se aceptó la concepción de que el conocimiento era la base para mejorar los aspectos sociales y económicos de la sociedad y el Estado tenía que ser el instrumento para lograr el progreso (Tanck, 1984: 5). En este siglo, la Nueva España encontró un momento de mayor urbanización. Los novohispanos aún mantenían su diversificación social, algunos de ellos habían logrado consolidarse como ricos mineros, comerciantes y hacendados; mientras que los pueblos de indios continuaban pagando su tributo a las autoridades virreinales.

Cabe destacar que, así como ocurrió en Europa, en la Nueva España comenzaron a propagarse algunos conceptos del movimiento Ilustrado. Dorothy Tanck (2006) explica que, en el caso novohispano, más que las lecturas de Voltaire o Rousseau fueron tres intelectuales españoles los que mayormente influyeron: Benito Feijoó (1676-1764), Pedro Rodríguez (1723-1803) Conde de Campomanes y Gaspar Melchor de Jovellanos (1744-1811). Las ideas educativas de todos ellos llevaron a una modernización de la educación tanto en la Metrópoli como en el virreinato. Las propuestas educativas de los ilustrados españoles se enfocaron en temas importantes para el progreso y mejora de España. Criticaron su situación adversa, así como el avance político y comercial de otras potencias europeas, principalmente de Inglaterra. La Península se encontraba en un estado de decadencia de la cual era necesario salir y la educación sería el medio más adecuado. 
En el caso de la instrucción de primeras letras, durante el reinado de Carlos III (1716-1788) hubo interés por expandirla, mejorarla y modernizarla. En esta modernización, además de la enseñanza religiosa se incorporaron conocimientos cívicos y técnicos. El primer paso que se dio fue la abolición del Gremio de Maestros en 1780 y la creación del Colegio Académico del Noble Arte de Primeras Letras. Con esta medida se buscó que el Estado borbón tomara "un papel más enérgico en promover la fundación de escuelas de primeras letras y en mejorar los planes de estudio" (Tanck, 1984: 12). En la Nueva España también se presentaron cambios importantes, ya que hacia finales del siglo el Ayuntamiento de la Ciudad de México propició la fundación de escuelas elementales gratuitas. A estos establecimientos se les comenzó a denominar como "escuelas públicas".

Ahora bien, ¿qué era una escuela pública? Para responder este cuestionamiento es necesario considerar que los conceptos son históricos; es decir, van cambiando en el transcurso del tiempo. De acuerdo con Eugenia Roldán Vera (2013), dicho concepto comenzó a utilizarse hacia finales del siglo XVIII, específicamente a partir del año 1780; sin embargo, su sentido o su significado variaban, esto de acuerdo al contexto o a la población. Existieron tres formas de utilizar el término. El primero de ellos era usado en los pueblos indígenas, pues en estas poblaciones una escuela pública era aquella que se sostenía por los fondos de la comunidad; algo que era compartido por todos, que era del pueblo y para el pueblo. En las ciudades habitadas por los españoles, criollos y mestizos, la situación cambiaba; las escuelas públicas eran aquellos establecimientos en los que los niños iban a aprender pero que no tenían funciones de internado, tal y como ocurría en los colegios. Por último, existió una acepción más que era utilizada para designar a aquellos "establecimientos financiados por el ayuntamiento como por la iglesia" (Roldán, 2013: 3). El concepto "público" fue cambiando en el transcurso del tiempo, de tal manera que, durante la transición de la vida virreinal a la independiente, la palabra "público" se comenzó a utilizar para diferenciar las escuelas públicas de aquellas que eran de carácter particular.

A partir de 1782 y hasta la primera mitad del siglo XIX, existieron los siguientes establecimientos escolares:

Escuelas gratuitas, dependientes de conventos y parroquias; éstas últimas se conocerían como escuelas pías y harían las veces de escuelas de caridad atendiendo gratuitamente a los vagos, a los hijos de viudas y otros: 2 . Escuelas gratuitas, financiadas con recursos procedentes de sociedades de beneficencia; 3. Escuelas gratuitas, para niños y para niñas por separado, financiadas por Ayuntamiento y municipios; 4. Escuelas particulares, a cargo de maestros autorizados por el gremio; 5. Amigas públicas gratuitas, para niñas de escasos recursos, a cargo de laicos organizados en cofradías; 6. Amigas particulares, donde una mujer proporcionaba algunos rudimentos de religión, a veces de lectura, y cuidaba niños muy pequeños y a las niñas; 7. Escuelas de caste- 
Ilano, establecidas en las parcialidades o pueblos de indios y financiadas por el gobierno civil. (Aguirre, 2002).

Hasta antes de la primera mitad del XVIII, los niños asistían a establecimientos propios para cada sexo, pero a partir de ese momento, un aspecto que comenzó a cobrar relevancia fue la homogenización de la instrucción elemental; es decir, dar los mismos conocimientos para los niños como para las niñas. Sin duda, esto último puede considerarse como un elemento renovador de la educación colonial puesto que, hasta antes de esta disposición, el aprendizaje había sido desigual.

En el caso de las mujeres, su educación e instrucción desde finales del siglo XVIII hasta los años sesenta del siglo XIX se fue consolidado en determinadas instituciones, principalmente, en los colegios femeninos. En ellos, además de los conocimientos de lectura y escritura, también se les enseñaron labores femeninas como la costura y el bordado. También se instruía en la fe católica, la cual se enseñó utilizando el sistema de catecismo para que las alumnas aprendieran de memoria los criterios para ser una buena cristiana que, para la época, significó un ideal de mujer entregada a la piedad y el desarrollo de virtudes como la laboriosidad, la obediencia y el cuidado de la familia. Entre estos colegios podemos mencionar el de la Caridad, el de San Miguel de Belén, "el de Inditas con maestras laicas indígenas; el de la Enseñanza, de monjas, y el de las Vizcaínas que, en 1793, abrió una gran escuela gratuita con maestras laicas" (Tanck, 2002: 261).

Los colegios también tuvieron una función social y cultural muy importante: el cuidado de las mujeres. Su reclusión en estas instituciones garantizaba la continuidad de su "virtud femenina". Evitaba que cometieran actos pecaminosos mientras llegaba el momento de tomar el hábito o de casarse.

Los planteamientos ilustrados que promovieron la modernización de la educación de las mujeres tuvieron otra consecuencia favorable para ellas, pues comenzó a surgir una incipiente "feminización del magisterio", un antecedente que permitió la expansión de la educación ilustrada, la alfabetización de las niñas y la [futura] construcción del estado Independiente (Arredondo, 2008: 38). Las mujeres experimentaron una trasformación profesional. Por primera vez, fueron capaces de ejercer un oficio: el de maestras, especialmente, porque al desaparecer el antiguo Gremio de Maestros, cualquier persona tuvo la posibilidad de abrir una escuela, situación que algunas mujeres aprovecharon para solicitar al Ayuntamiento el permiso y abrir un establecimiento educativo. Sin embargo, el hecho de que ahora pudieran ejercer la enseñanza, no quiso decir que el mundo predominantemente masculino del magisterio cambiara repentinamente; por el contrario, las mujeres interesadas en la enseñanza trabajaron en un campo acotado de acción: el de las primeras letras. Sin embargo, además: 
Toda la educación giraba en torno a la imitación de modelos, dignos de seguir. El maestro tenía que ser pulcro, bien vestido, español, cristiano y de buenas costumbres. Había de saber leer en libros y en cartas. Escribir los diversos tipos de letras. Conocer bien las cinco reglas de cuentas: sumar, restar, multiplicar, medio partir y partir por entero. Además de sumar cuenta castellana. (Reyes, 1984: 24).

En el caso de las maestras de "amiga", se tenían que acreditar los conocimientos especiales y necesarios para instruir a los niños, tal y como lo hacían los maestros varones; sin embargo, aún no era una obligación examinarse, únicamente acudían al ayuntamiento a solicitar una licencia para abrir su establecimiento y cumplir con una labor principal: "enseñar catecismo y buenos modales" (Gonzalbo, 1990: 39).

En términos culturales, las mujeres debían ser apegadas a la religiosidad, a una moral devota y cristiana y dentro de un modelo familiar. La mujer tenía en su vida una misión muy importante y esa era la maternidad y el cuidado de los hijos, se pensaba que la vida doméstica era su principal actividad. De allí que las niñas y jóvenes se educaran con esos parámetros socioculturales, no obstante, esto no quiere decir que no existiera una preocupación por que este sector de la población tuviera acceso a la instrucción. Si bien las niñas debían ser formadas, educadas e instruidas dentro de un modelo religioso en el que la piedad y laboriosidad femenina eran indispensables, por otra parte se planteó que había que "dotarlas de los conocimientos y habilidades para ser madres y esposas" (Arredondo, 2003: 7) y eso implicaba enseñarles los conocimientos elementales, es decir, las primeras letras.

Con la independencia de México, la educación de los más jóvenes seguía siendo una preocupación. Dotar a la población de conocimientos era indispensable para formar una nueva identidad nacional, en la que se abandonaba la figura de súbdito para obtener la de ciudadano. Fue difícil que los diferentes gobiernos mexicanos que estuvieron al frente de la nación entre 1821 a 1860 lograran abrir escuelas para dotar a su pueblo de la educación que tanto anhelaban. Los niños y niñas seguían asistiendo a las escuelas públicas instaladas en las parroquias o conventos, aún había preceptores particulares ofreciendo sus servicios a las élites y las escuelas de "amiga" seguía siendo una alternativa de instrucción para muchas niñas, lo mismo que los colegios femeninos. La falta de liquidez económica del estado mexicano propició en gran medida esta continuidad.

Cabe destacar que, pese a las dificultades políticas y económicas por las que atravesaba la nación mexicana, si hubo un proyecto educativo que se fue afianzando durante el periodo de 1822 a 1850, me refiero al sistema lancasteriano, un modelo que garantizaba una instrucción masiva y económica. En 1822 se fundó una asociación filantrópica para la enseñanza de las primeras letras. Esta fue de carácter privado y se conoció con el nombre de "La Compañía Lancasteriana". La enseñanza proporcionada por la compañía gozó de popularidad y reconocida reputación, en especial por el apoyo que recibió de parte del gobierno mexicano. Su 
éxito se debió también al hecho de que fue económica y funcional, ya que con un solo maestro era posible educar a una gran cantidad de niños. De acuerdo con Anne Staples, la organización de la escuela fue de la siguiente manera:

Dividida en tres departamentos: de enseñanza primaria, con lectura, escritura, elementos de aritmética y catecismo cristiano y civil, [...] de enseñanza normal para preparar maestros de primeras letras con el nuevo método lancasteriano en un curso de seis meses [...]; las de artes y oficios, dividida en seis clases: dibujo lineal, matemáticas, geografía, historia, mitología y latinidad (Staples, 2014).

En términos educativos, la primera mitad del siglo XIX fue muy compleja. Se sucedieron diversas legislaciones en favor de la educación, así como varios proyectos educativos que no lograron consolidarse. ${ }^{2}$ La situación se hizo aún más compleja cuando, en 1824, se adoptó el federalismo. Con él, se garantizaba que cada entidad estatal tendría autonomía para ejercer sus derechos políticos, civiles y económicos. A pesar de las diferencias políticas que los liberales sostuvieron con los conservadores, hubo un punto en el cual ambos bandos estuvieron de acuerdo: instruir a la población y por tanto legislar en materia educativa. El Estado y las leyes serían el camino para crear una sociedad instruida y, en el caso de la enseñanza, de las primeras letras ésta: "había quedado dentro de la esfera de la influencia de los estados, ayuntamientos y pueblos" (Staples, 2002: 50).

De los años veinte a la década de 1860, la instrucción elemental fue impartida en las escuelas municipales, las establecidas en los conventos, las particulares, las de "amiga" y con La Compañía Lancasteriana; en todas ellas se instruyó a los niños en las primeras letras. Las escuelas particulares fueron incrementándose debido a que, a pesar de la importancia que el gobierno dio a la apertura de escuelas públicas, la inestabilidad política y la realidad económica del país imposibilitó que esta medida fuera completamente exitosa. Generalmente, se dependió de otros establecimientos en los que ya se había establecido una escuela, como en el caso de las parroquias. Las escuelas particulares pudieron satisfacer la demanda educativa de aquellos sectores que contaron con la solvencia económica para poder educar a sus hijos. El Estado vio limitada su capacidad de abrir nuevas escuelas elementales y en los estados, se presentaron diversos problemas que tampoco ayudaron al establecimiento de un verdadero sistema educativo durante la primera mitad del siglo XIX.

Para finalizar este apartado, quiero agregar que, además de las escuelas públicas fundadas por los cabildos y los ayuntamientos de las ciudades, también algunas asociaciones particulares lo hicieron. Ese fue el caso de la cofradía de Nuestra Señora de Aránzazu, que

2 Dichos proyectos educativos correspondieron a los años de 1826, 1827, 1832, 1833, 1834 y 1843. 
fundó unas escuelas públicas en el Colegio de San Ignacio de Loyola y que permanecieron en funciones desde 1793 a 1844.

\section{Las escuelas públicas de "San Luis Gonzaga" 1793-1844}

En 1767 los vascos y navarros residentes en la Nueva España y, que se habían organizado en la cofradía de Nuestra Señora de Aránzazu, abrieron un establecimiento destinado a la salvaguarda y protección femenina. Su institución recibió en nombre de Colegio de San Ignacio de Loyola; en él se recibían mujeres viudas y huérfanas españolas, preferentemente de origen vascongado. Poco a poco el colegio "de las Vizcaínas" fue cobrando relevancia, no sólo por la labor asistencial de los cófrades vascongados, sino también por la importancia que ellos le dieron a la instrucción femenina.

Para los vascos y navarros, era necesario que la mujer tuviera educación e instrucción, pues de esta manera lograría realizar de una forma más eficaz sus labores domésticas y maternales. Para ellos, el hogar era el primer medio en el cual los niños recibían conocimientos, es por ello que las madres debían saber leer, escribir y contar, saberes que complementarían sus habilidades femeninas sobre costura y bordado.

Entre saber leer, escribir y contar, es muy probable que la lectura haya sido la más fomentada, pues para los vascongados, las madres de familia tenían que hacer lecturas devocionales y piadosas, de esa manera podrían transmitir a sus pequeños los valores morales propios de la religión cristiana. De allí que las colegialas de San Ignacio dedicaran gran parte de su tiempo a estas actividades (Torres, 2020). Para los vascos, el Colegio de San Ignacio de Loyola era su mayor obra asistencial; sin embargo, ellos no se limitaron a atender, proteger, educar e instruir a las mujeres españolas que pedían asilo en su establecimiento, también lo hicieron hacia otros sectores de la población femenina de la ciudad de México, esto a través de la organización y apertura de unas escuelas públicas.

En el año de 1793, en atención al Ilamado civil de la corona española y del Ayuntamiento de la Ciudad de México sobre la conveniencia de favorecer la instrucción de los niños en escuelas públicas, la Mesa de Aránzazu, el órgano rector del Colegio de San Ignacio, aceptó alistar un espacio en el edificio que albergaba su colegio para establecer una escuela de este tipo. A veintitrés años de que el establecimiento entrara en funciones, el señor presbítero Francisco Manuel Zorrilla dispuso en su testamento que se llevara a cabo una obra pía, en la cual se beneficiara en términos educativos, a las "niñas pobres" cuyas familias no pudieran solventar sus estudios. La donación fue de 9,000 pesos para la "solemne apertura de las escuelas, que se instalaron en la planta baja del edificio" (Luque, 1995: 280). La petición fue 
llevada a la Mesa del colegio a través del Diputado José Patricio Fernández de Uribe (17421796) quien era el albacea del difunto Zorrilla.

En la junta de cabildo celebrada en 1790, Uribe expuso a la Mesa de Aránzazu el deseo de Manuel Zorrilla; también habló sobre la cantidad de dinero que éste había dejado para la fundación de una escuela gratuita para niñas que fueran menores de trece años. La petición fue recibida favorablemente, por lo que prontamente se elaboró un proyecto para la dirección de esta escuela. Por medio de un aviso público y con la autorización del virrey Francisco de Güemes y Horcasitas segundo conde de Revillagigedo (1738-1799), las escuelas públicas se abrieron el 21 de junio de 1793. Dichos establecimientos fueron nombrados en honor a San Luis Conzaga, un religioso jesuita de origen italiano que había sido beatificado en el año de 1605 y que, para 1726, el papa Benedicto XIII (1649-1730) canonizó. A partir de ese momento, fue nombrado como el santo patrono de la juventud.

Se recibieron a niñas de pocos recursos económicos y de distintas condiciones sociales para instruirlas en la doctrina cristiana, en la lectura, la escritura, el conteo y en las labores de la costura, el bordado, el tejido de aguja y la elaboración de diferentes clases de flores. En el aviso público que la Mesa de Aránzazu hizo, se solicitó que los padres que lo desearan enviaran a sus hijas a las escuelas públicas de "San Luis Gonzaga" y se les recomendó que lo hicieran de manera responsable. Pidieron que, cuando fuera posible, proveyeran a sus hijas o recomendadas de los materiales indispensables para su aprendizaje, además de cuidarlas y acompañarlas en el momento de asistir o salir de sus clases. Los interesados en enviar a sus hijas a estas escuelas debían, a partir de la publicación del aviso, presentarse en la portería del Colegio para solicitar informes y para realizar la inscripción de la niña.

Es interesante observar cómo, en el caso de las escuelas públicas, se aceptaron niñas de cualquier condición social, algo que se diferenciaba de las características o requisitos de ingreso que los vascos tenían para su colegio, pues en dicha institución solo se recibiría a mujeres españolas que comprobaran su limpieza de sangre a través de su fe de bautismo. También hay que destacar que la enseñanza en las escuelas públicas fue independiente; es decir, que no hubo ni se planteó ninguna relación con las colegialas y lo que éstas hacían al interior del Colegio de San Ignacio de Loyola. No obstante, para la Mesa de Aránzazu fue importante que tanto en su colegio como en las escuelas públicas existiera un buen comportamiento, pues lo consideraban como una parte esencial en la enseñanza y aprendizaje de las niñas. De igual manera, sostuvieron que la relación maestra-alumna únicamente debía tratar los asuntos escolares y educativos más que afectivos. La maestra debía ser: "del todo graciosa sin que se permitan a las discípulas el menor obsequio á las maestras; y ni aun con pretexto de piedad ó debocion podrán llebar á la escuelas, belas, flores" (AHCV, E6, TIV, V2, NC 15029). 
Las escuelas públicas de "San Luis Gonzaga" fueron exitosas; de acuerdo con Josefina Muriel (2006), el número de niñas que asistieron a esta escuela fueron quinientas. La Mesa dotó a las escuelas de reglamentos provisionales (educación formal) y de todos los materiales para el aprovechamiento de las niñas, entre ellos: cartillas, libros, seda, agujas y almohadillas. El horario de entrada era "desde las $8 \mathrm{~h}$ hasta las nueve por la mañana, y por la tarde desde las 3 hasta el quarto; debiendo salir alas 12 y alas 5" (AHCV, E6, TIV, V2, NC15029).

En los documentos que se han consultado en el Archivo Histórico "José María Basagoiti Noriega" del Colegio de las Vizcaínas, y que tratan sobre estas escuelas, no se especifica si era uno o varios espacios en los que se instalaron las escuelas de "San Luis Gonzaga", pero por lo que se puede leer en la cita anterior, la existencia de dos turnos disponibles para que las niñas asistieran a estudiar puede explicarnos por qué se referían a ellas en plural.

En 1803 apareció un Reglamento para la dirección de las escuelas públicas fundadas en el Real Colegio de San Ignacio de Loyola. En él, se ratificó que éstas estaban bajo la protección y patronato de la Mesa de la Cofradía de Nuestra Señora de Aránzazu. El reglamento fue escrito por Don Juan Bautista de Arechederreta (1771-1836), miembro y Diputado de la Cofradía. En ese año, fue nombrado comisionado de las escuelas públicas. En el capítulo tercero del Reglamento, se hizo referencia a que en las escuelas públicas concurrieron: "Niñas de la primera distinción [a las] que se procurará tratar con la delicadeza que merece su nacimiento, pero de un modo que no les sea sensible á las que no tuvieron la fortuna sino de nacer de Padres humildes" (AHCV, E6, TIV, V10, N C 14709). Que niñas españolas asistieran a las escuelas públicas del Colegio confirma que la institución contaba con un reconocimiento entre la población novohispana que vivía en la capital del virreinato. De igual manera, resulta interesante ver cómo los miembros de la Mesa decidieron que las niñas que no tuvieran la condición de española, fueran tratadas de la misma manera, sin privilegiar a ninguna ya que, de acuerdo con Bautista Arechederreta, la instrucción que las niñas recibían tenían el objetivo de "hacer nacer en ellas los más solidos sentimientos de honor y de honestidad que es el patrimonio mas apreciable á las personas de su sexo" (AHCV, E6, TIV, V10, NC14698).

En el reglamento también se estableció que la Mesa de Aránzazu contaba con sus propias facultades y prerrogativas, entre ellas nombrar a uno de sus Diputados para que fuera el Director de las clases, y así con "su carácter y respeto se concilie mejor el amor y la obediencia de las Niñas Educandas" (AHCV, E6, TIV, V10, NC14700). Para cumplir con este objetivo, el Diputado que fuera comisionado debía encargarse de visitar con frecuencia las clases y observar el método que fuera más fácil y conveniente para el aprovechamiento de las niñas, así como observar:

... quienes son las mas aprovechaditas y mas asistentes para cuando llegue el caso de distribuir los premios: de compararles, aquellos Autores mas sanos para que se ins- 
truyan por las Maestras en la Doctrina Christiana y Dogmas de Ntra Santa Religión. (AHCV, E6, TIV, V10, NC14700).

Ahora bien, ¿Se puede tener conocimiento sobre el aprovechamiento de las niñas en estas escuelas? La documentación que hasta el momento se ha localizado y revisado, no contiene datos de la forma en la cual eran calificadas, pero se sabe que la verificación de los conocimientos y, por tanto del aprovechamiento de las alumnas, se hacía por medio de certámenes que consistieron en poner a dos niñas, las cuales realizaban una serie de preguntas con sus respectivas respuestas; la vencedora era "la que había obtenido mayor número de aciertos y era acreedora a un premio" (Deveaux, 2008: 77).

Las escuelas fueron sostenidas por la Mesa de Aránzazu, quien otorgaba los fondos para mantener el proyecto. De hecho, el propio Diputado Comisionado debía recoger, del tesorero del Colegio de San Ignacio, los fondos destinados para las "escuelas públicas". Para el año 1803, el capital del que se dispuso fue mil ochocientos pesos anuales. Con ese dinero se pagó a las maestras, ellas recibieron 100 pesos anuales; el salario recibido se repartió en tercios durante el año de trabajo. La distribución de premios fue importante. En la ceremonia de premiaciones, la Mesa era la invitada de honor y el evento se realizaba en junio, dos o tres días antes o después de la celebración de San Luis Gonzaga, que era el día veintiuno. Para realizar la ceremonia, se le avisaba en primer lugar a la señora prefecta y ella a su vez notificaba a las maestras y alumnas para que:

Todo esté con el mayor aseo, y curiosidad, de suerte que si concurriesen á este acto algunas personas de caracter, no tengan que notar cosa alguna en una Casa de Niñas bien criadas; pero que esto se entienda por lo respectivo á la limpieza y aseo y no con una profanidad que ocasionaria gastos, introducieria en luxo y la vanidad, vicios muy frecuentes en semejantes concurrencias por lo que debe entenderse, privado y prohibido el adorno de Cortinas y tapices, ecepto el de las bancas de la Yltre Mesa, y mucho mas, la compostura de Alhajas, Joyas y vestidos costosos en las Discipulas, de suerte que todas deberan presentarse en sus pobres, y comunes trapos; pero limpias y peinadas, y la que quisiere venir en otro modo, no se le admitirá sea quien fuese y en la observancia de este punto se deberá celar cuidadosamente, para evitar las consequencias que de su infraccion deberian resultar insensibles a fin principal de la ereccion de las Escuelas, (AHCV, E6, TIV, V10, NC14703).

Como se puede apreciar en esta cita, la vida cotidiana al interior de la escuela era exigente y rigurosa. El orden establecido para el seguimiento de las clases fue llevado a la práctica por las señoras Prefectas. Quienes cumplían estas funciones fueron la Rectora y la Vice-Rectora del Colegio de San Ignacio de Loyola. Ellas fueron las principales encargadas de la organización económica y del gobierno de las escuelas públicas. Generalmente fue la Vice-rectora 
quien se desempeñaba como prefecta, pues se quería evitar que la Rectora se distrajera de sus obligaciones en el Colegio. Su principal trabajo era mantener y conservar el buen orden, así como hacer efectivas las decisiones de la Mesa sobre la educación y aprovechamiento de las niñas.

La labor de las Prefectas fue amplia, pues de ellas dependió el buen funcionamiento de las escuelas públicas. También eran ellas las que rendían cuentas sobre el aprovechamiento de las niñas, no las maestras, éstas últimas fueron consideradas como las subalternas de las Prefectas. Las maestras únicamente debían cumplir con su trabajo de enseñanza, y así convertir a las niñas en lo que Juan Bautista de Arechederreta llamó "plantas con frutos dulces".

Las Prefectas eran las encargadas de abrir y cerrar las puertas a la hora de entrada y salida de las niñas. No podían faltar a este acto; de allí, la importancia que tuvo que fueran dos las mujeres que cumplieran con esta obligación (Rectora y Vicerectora). En el caso de que alguna se ausentara, estaba la otra para suplirla; sólo en casos extraordinarios se podía solicitar a la secretaria del colegio su apoyo. Otro de sus deberes fue el de evitar que las colegialas pasaran al lugar en donde se establecieron las escuelas públicas, tampoco que las niñas de este establecimiento visitaran el Colegio. Esto último fue prohibido, las maestras fueron las únicas autorizadas para pasar de un lugar a otro y esto solo para dar sus clases. Esta medida aseguraba que el orden y la calma que se tenía en el establecimiento no fuera trastocado, tampoco se generarían pláticas "insanas" entre las colegialas con las alumnas de las escuelas públicas, pues éstas últimas eran las que tenían contacto con el exterior.

La elección de las maestras debía hacerla la prefecta principal, y el Diputado Comisionado también debía observar el proceso de selección. La decisión dependió de "su instrucción, virtud y buen estilo para el mayor aprovechamiento de las Niñas" (AHCV, E6, TIV, V10, NC14701). En opinión de Don Juan Bautista de Arechederreta, elegir a las maestras debía ser un punto en el que se debía poner el cuidado más escrupuloso, porque de eso dependería el éxito o fracaso de las escuelas.

¿Quiénes cumplieron la función de las maestras? ¿Cómo las escogieron los cófrades de Aránzazu? Las maestras seleccionadas fueron colegialas De San Ignacio, se debía procurar escoger a las más instruidas, hábiles y virtuosas, ya que con su ejemplo se debía educar a las niñas, no solo en el ejercicio de su instinto femenino sino también en el "santo temor de Dios", que para los vascos y navarros de Aránzazu era el principio de toda buena educación. Hasta el momento en que se presenta este texto, no se ha podido localizar más información que permita conocer o precisar detalles sobre las maestras. Quiénes eran, cómo fueron nombradas, cómo enseñaron, son cuestionamientos que quedan pendientes por resolver.

A pesar de que no hay muchos datos sobre las maestras, ha sido posible saber que la salud era un punto importante. Ellas debían ser personas saludables, esto evitaría faltas y atrasos que perjudicaran el avance de la instrucción de las niñas, pero también evitaba cargas 
de trabajo extra para las demás maestras. Bautista Arechederreta estuvo consciente de que una enfermedad grave e incluso la muerte no era algo ajeno al día con día, si se llegaba a presentar alguna de estas situaciones, fue obligación de la señora prefecta encontrar el remplazo de aquella maestra que quedara imposibilitada o que falleciera.

La buena conducta fue otro elemento que debían cumplir las maestras; si por alguna razón, alguna de ellas mostraba "mal genio" o "impertinencia de edad", la prefecta podía removerla de su cargo. En este caso, el Diputado comisionado debía estar enterado de la remoción. Las maestras debían cumplir cabalmente con sus obligaciones; es decir, la asistencia diaria y constante a sus clases, así como prestar atención y cuidado a sus actividades. Por ningún motivo debían distraerse de sus ocupaciones. Ellas tenían la responsabilidad de cumplir con su principal obligación que era el cuidado e instrucción de las niñas. De esta forma, cuando estaban enseñando en las escuelas públicas, no podían hacer las actividades y labores propias de una colegiala de San Ignacio; de tal manera que: "las costuras y labores propias de las Maestras no las deveran hacer en las Escuelas sino en sus viviendas á las horas que tengan desocupadas pues allí deberan baxar sin otra ocupacion mas que las Discipulas". (AHCV, E6, TIV, V10, NC14708). Las maestras debían encaminar a las niñas a la docilidad y al amor; debían inculcar en ellas los principios de honor y honestidad.

Los cófrades de Aránzazu se ocuparon por extender sus prácticas culturales hacia otras niñas que no necesariamente eran de su mismo origen étnico. El interés fue que todas las mujeres debían ser instruidas y educadas para desenvolverse correctamente en sus labores cotidianas; de esta manera, si las niñas desde temprana edad asistían a la escuela y adquirían aprendizajes, se evitaría que fueran ociosas, convirtiéndose así en buenos ejemplos para su futura maternidad.

Las escuelas públicas sostenidas por la Cofradía y la Mesa de Aránzazu estuvieron en constante peligro de ser cerradas, principalmente, por las problemáticas económicas causadas por las constantes solicitudes de préstamos por parte de los gobiernos mexicanos al Colegio de San Ignacio. Por el momento se desconoce más sobre las dificultades económicas de estas escuelas, la información que se ha localizado no ofrece detalles al respecto, por lo que no se puede afirmar en qué momentos hubo mayor o menor crisis financiera. Lo que sí se puede asegurar es que, pese a esas dificultades, los vascongados se empeñaron por mantenerlas abiertas, por lo que estas continuaron funcionando a lo largo de la primera mitad del siglo XIX, esto es hasta 1844.

Como se mencionó en el apartado anterior de este artículo, el sistema lancasteriano era considerado como una buena alternativa para educar a los niños. Este modelo educativo fue adoptado para la enseñanza de las niñas de las escuelas públicas de "San Luis Gonzaga". En 1843, cuando Joaquín Baranda (1840-1906) fungía como Ministro de Instrucción, las escuelas públicas tuvieron una visita de inspección por parte de una comisión de la Compañía 
Lancasteriana. En esos momentos, esta última estaba a cargo de la Dirección de la Educación Elemental en el país. Al final de la examinación, los comentarios sobre las escuelas públicas, sobre sus maestras y alumnas y del sistema de enseñanza, fueron favorables. Considero que esto ratifica la importancia que los vascongados le concedieron a la formación de las mujeres. Abrir las escuelas públicas fue otra muestra de la intención que esta comunidad, por lo menos la que se encontraba integrada a la Cofradía de Nuestra Señora de Aránzazu de la Ciudad de México, tuvo al fomentar la educación e instrucción femenina y, en este caso, no sólo de las españolas o de las de ascendencia vascongada, sino también de las niñas de otros orígenes étnicos.

En 1843, las escuelas públicas tuvieron un nuevo programa de enseñanza, el Plan de Enseñanza de Instrucción Primaria que se sigue en las escuelas públicas en el Colegio Nacional de niñas del Sr. San Ignacio de Loyola. Al revisar el documento y observar el contenido de las materias que las niñas estudiaban, es posible darse cuenta que, en estas escuelas, se seguía al pie de la letra la enseñanza lancasteriana. Las estudiantes aprendían Religión, Lectura, Escritura, Costura, y Aritmética. (AHCV, E4, TV, V2, NC16829-16869).

En el plan escolar se detallan los materiales que las niñas ocuparon en sus clases. Así, para la clase de religión se utilizó el catecismo del padre Jerónimo Martínez de Ripalda, publicado por primera vez en el año de 1616 y que fue utilizado con el objetivo de poner al alcance de los niños las bases de la doctrina cristiana (Arredondo, 2002). Otros materiales que se utilizaron fueron el catecismo de Claude Fleury; el Silabario de San Vicente que fue utilizado para aprender lectura, mientras que "pizarras, pizarrines y tablitas", fueron utilizados para la clase de escritura. En aritmética se usó el catecismo de Urqullu y, finalmente, para la clase de costura se hizo uso de "tela, agujas, dedales, bolitas de hilo, tijeras" (AHCV, E6, TIV, V10, NC16829-16869). El Plan no contiene el nombre del o los autores del mismo.

Las escuelas públicas contaron con una dinámica en la que las alumnas no residían en el establecimiento; diariamente asistían a sus clases y, al término de estas, se retiraban a sus hogares. Se seguía un plan de enseñanza formal que guiaba los estudios y la manera en la cual las alumnas debían aprender. Ellas eran evaluadas en cada uno de sus aprendizajes; de hecho, desde que estas escuelas fueron abiertas, se fomentó la premiación de aquellas que demostraban sus adelantos y progresos.

\section{Conclusiones}

Acercarse a las escuelas públicas de "San Luis Gonzaga" del Colegio de San Ignacio de Loyola abre la posibilidad de comprender un aspecto más de la educación femenina en México en tiempos pasados. En estas escuelas no hay una novedad educativa, pues, en cierto modo, se 
mantuvieron vigentes las ideas sobre los contenidos que las mujeres debían aprender desde finales del siglo XVIII hasta las primeras cuatro décadas del XIX. Lo que la apertura de estas escuelas nos muestra es algo que podemos considerar como significativo para una comunidad específica de la capital de la Nueva España y, posteriormente, para el México independiente; y este fue el interés que los vascongados tuvieron por contar y sostener con un establecimiento que diera cabida a más niñas, esto independientemente de lo que hacían por su Colegio. De esta manera, contribuyeron a ampliar la posibilidad de las niñas y mujeres de la época de tener acceso a la instrucción y a la educación. La solvencia económica de los integrantes de esta cofradía fue un factor clave para la continuidad de las escuelas públicas en el lapso de 1793 a 1844, siendo un establecimiento que posiblemente también fue exitoso al igual que el propio Colegio de San Ignacio.

Sin embargo, hay que reconocer que no todo debió haber sido favorable o positivo. Lamentablemente, la principal dificultad que se tuvo durante la investigación y la posterior escritura de este texto fue la parcialidad de las fuentes. Una parcialidad que tiene dos sentidos. El primero de ellos es que las fuentes consultadas son oficiales, es decir, producidas por los hombres que dirigían el establecimiento, por lo cual ha sido muy difícil tener acceso a otros documentos en los cuales se presente otra visión de los hechos; por ejemplo, informes de las maestras, exámenes o calificaciones de las alumnas o incluso la opinión de estas mismas sobre su educación o su vida cotidiana en estas escuelas públicas. La segunda forma de entender esta parcialidad tiene que ver con el número de las mismas, es decir, fueron muy pocos los documentos que se pudieron rastrear y consultar, pero esto no quiere decir que se haya dado por concluida la investigación; al contrario, esto da pie a continuar buscando y así completar la información que se ha presentado.

Pese a las limitaciones, este artículo ha buscado contribuir al conocimiento de la educación femenina en el pasado, un aspecto que en la historiografía reciente de la educación mexicana ha cobrado relevancia; las mujeres (niñas, jóvenes y adultas) forman parte del entramado histórico y es por ello que hay que sacarlas a la luz, hay que hacerlas visibles, su presencia e importancia en el devenir del tiempo se debe analizar desde diversos puntos de vista, pero las cuestiones sociales y culturales, nos van a dar las claves para comprenderlas como sujetos históricos.

\section{Fuentes}

\section{Archivos}

Archivo Histórico "José María Basagoiti Noriega" del Colegio de San Ignacio de Loyola, Vizcaínas. Documentos de archivo 
Archivo Histórico Colegio de las Vizcaínas, Fondo Real Colegio de San Ignacio de Loyola (siglos XVIIIXX), Estante 6, Tabla IV, Volumen 2, Número de Cómputo 15029.

Plan de Enseñanza de Instrucción Primaria que se sigue en las escuelas públicas en el Colegio Nacional de niñas del Sr. San Ignacio de Loyola. Histórico Colegio de las Vizcaínas, Fondo Real Colegio de San Ignacio de Loyola (siglos XVIII-XX), Estante 4, Tabla V, Volumen 2, Número de Cómputo 1682916869.

Reglamento para la direccion de las Escuelas Publicas fundadas en el Real Colegio de Niñas de San Ignacio de Loyola, baxo la proteccion y Patronato de la Ylustre Mesa de ka Cofradía de Nuestra Señora de Aranzázu de Mexico Hecho en el año 1803 Por el Doctor Don Juan Bautista de Arechederreta Diputado de la misma Ylustre Cofradia y actual Comisionado de estas Escuelas, Archivo Histórico Colegio de las Vizcaínas, Fondo Real Colegio de San Ignacio de Loyola (siglos XVIII-XX), Estante 6, Tomo IV, Volumen 10, Número de Cómputo 14709, 14698, 14700, 14701, 14703 y 14708.

\section{Hemerografía}

Tanck de Estrada, Dorothy (2002), "El gobierno municipal y las escuelas de primeras letras en el siglo XVIII mexicano", Revista Mexicana de Investigación Educativa, núm. 15, vol. 7, mayo-agosto, pp. 257278.

\section{Bibliografía}

Arredondo, María Adelina (coord.) (2003), Obedecer, servir y resistir. La educación de las mujeres en la historia de México, Universidad Pedagógica Nacional, México.

Arredondo, María Adelina (2008), "De 'amiga' a preceptora: las maestras del México independiente" en Luz Elena Galván Lafarga y Oresta López Pérez (coords.), Entre imaginarios y utopías: historias de maestras, CIESAS/El Colegio de San Luis, México. pp. 37-68.

Deveaux Cabrera, Nora Socorro (2008) "Las reformas educativas en México y su impacto en la enseñanza del Colegio de San Ignacio de Loyola, Vizcaínas, 1821-1910", tesis de licenciatura, Escuela Nacional de Antropología e Historia, México.

Galván Lafarga, Luz Elena y Oresta López (2008), Entre imaginarios y utopías: historias de maestras, CIESAS/El Colegio de San Luis, México.

Gonzalbo Aizpuru, Pilar (1990), Historia de la educación en la época colonial. La educación de los criollos y la vida urbana, El Colegio de México, México.

Luque Alcaide, Elisa (1995), La Cofradía de Aránzazu de México (1681-1799), Ediciones Eunate, Pamplona, España.

Muriel, Josefina (2006), Los Vascos en México y su Colegio de las Vizcaínas, Integración editorial S.A. de C.V., México.

Staples, Anne (2002) "Los poderes locales y las primeras letras", en Pilar Gonzalbo Aizpuru (coord.), Historia y nación (Actas el Congreso en homenaje a Josefina Zoraida Vázquez) I. Historia de la educación y enseñanza de la historia, El Colegio de México/Centro de Estudios Históricos, México, pp. 47-61.

Tanck de Estrada, Dorothy (1984) La educación ilustrada, 1786-1836. Educación primaria en la Ciudad de México, El Colegio de México, México.

Torres Alejo, Andrea (2020), "Flores de la piedad. La educación devocional y las prácticas religiosas en el Colegio de San Ignacio de Loyola. 1767-1861" en Belinda Arteaga Castillo (Coord.) Educación a debate: investigaciones sobre la problemática mexicana, siglos XVIII-XX. Universidad Santiago de Cali, Colombia pp. 17-54 


\section{Publicaciones electrónicas}

Aguirre Lora, María Esther (2002) "Una invención del siglo XIX. La escuela primaria (1780-1890)" en Luz Elena Galván Lafarga (coord.) Diccionario de Historia de la Educación, Universidad Nacional Autónoma de México/Consejo Nacional de Ciencia y Tecnología/Centro de Investigaciones y Estudios Superiores en Antropología Social, México, disponible en: http://biblioweb.tic.unam.mx/ diccionario/ (fecha de consulta: 15/11/2019).

Arredondo, María Adelina (2002) "El catecismo de Ripalda" en Luz Elena Galván Lafarga (coord.) Diccionario de Historia de la Educación, Universidad Nacional Autónoma de México/Consejo Nacional de Ciencia y Tecnología/Centro de Investigaciones y Estudios Superiores en Antropología Social, México, disponible en: http://biblioweb.tic.unam.mx/diccionario/ (fecha de consulta: 15/11/2019).

Galván Lafarga, Luz Elena (2002), Diccionario de Historia de la Educación, Universidad Nacional Autónoma de México/Consejo Nacional de Ciencia y Tecnología/Centro de Investigaciones y Estudios Superiores en Antropología Social, México, disponible en: http://biblioweb.tic.unam.mx/diccionario/ (fecha de consulta: 15/11/2019).

Meníndez Martínez, Rosalía (2009), "La historia de la educación en México: nuevos enfoques y fuentes para la investigación", Sarmiento Anuario Galego de Historia da Educación, núm. 13, documento pdf, disponible en: https://www.udc.es/dep/pdce/Sarmiento/SARMIENTO\%2013\%20WEB.pdf (fecha de consulta: 15/11/2019).

Reyes Morales, Cayetano (1984) "Un día de clases en la época colonial", en www.colmich.edu.mx/relaciones25/files/revistas/020/CayetanoReyesMorales.pdf (fecha de consulta: 18/11/2019).

Roldán Vera, Eugenia (2013), "Escuela pública: orígenes de un concepto. Ca. 1770-1838”, Memoria electrónica del XII Congreso Nacional de Investigación Educativa, aportes y reflexiones para la mejora educativa, vol. 1, año 1, documento pdf, disponible en: https://www.academia.edu/5304740/ Escuela p\%C3\%BAblica or\%C3\%ADgenes de un concepto ca. 1770-1838 (fecha de consulta: 15/11/2019).

Staples, Anne (2014) La educación en México. El siglo XIX, primera parte, disponible en: https://www. youtube.com/watch? $v=$ hcunGadl 8E (fecha de consulta: 118/11/2019). 